\section{Evi Puspitasari}

took her undergraduate degree in Universitas Negeri Yogyakarta (UNY) for

English Education program. She graduated from English Language Studies program at Universitas Sanata Dharma (USD),

Yogyakarta. She is interested in Material Development and Evaluation, Teaching Methodology, and Teachers' Cognition. She is now teaching in English Education Department, Universitas Muhammadiyah Yogyakarta (UMY).

\section{9-60}

\title{
Literature-Based Learning to Build Students' Vocabulary
}

\begin{abstract}
Literature-based Approach ( $\mathrm{LbA}$ ) is popularly used in reading. In implementing the approach, teachers use literary works to be read by students. The literary works that the students read to get the language input are commonly authentic which means that by reading the texts, students can identify a model of language and several aspects of language such as expression, vocabulary, grammar, and culture and how to use them in a real context. Realizing the importance of input, a teacher in a university in Indonesia implemented this approach in a reading class for freshmen. This research which belongs to descriptive qualitative research put attention on investigating what the students perceived toward the implementation of the LbA to assist them in vocabulary building. The data were collected by interviewing five students who were chosen because it was their first time reading an English language novel and they were the top six students in terms of vocabulary scores. To interview the participants who are presented using pseudonym, a semi guided interview guideline was used as an instrument. The research results show that students were anxious joining this class at the beginning. However, after some meetings and reading several pages, they started to enjoy reading the novel because the novel was interesting and entertaining. In addition, the topic was closely related to their daily life. After getting new words, one of participants wrote them on paper and stuck it on her room wall. Four other students wrote the words on a notebook as a vocabulary journal. Besides by doing those things to help them recall the words, the students also used them in retelling quizzes for writing and in daily conversation with mates for speaking.
\end{abstract}

\section{INTRODUCTION}

Literature-based Approach (LbA) is one of ways in using authentic materials. Tomlinson (2008) puts authenticity as one of requirements for good instructional materials. He states that with authentic materials, students get more opportunities to know the target language because authentic materials provide original expressions and vocabulary used in the countries where English is used 
as a daily language. Using authentic materials, this approach is usually done using texts; thus, reading becomes the main skill that will be focused on. In applying Literature-based Approach, literary works such as poetry, short stories, plays, and novels are the ultimate instrument (Norland \& Pruett-Said, 2006). Through those authentic works, teachers do not only develop students' language skills or cognitive skills as things to learn, but also work on students' emotion skills or affective skills.

In Indonesia, English teachers commonly use text types to build students' vocabulary through reading. Instead of using literary works, text types such as narrative, procedure, recount, descriptive, or expository are more preferred in reading classes. In fact, the texts may not always be presented in one unity of story, and many times, they do not have relation from one to the other. Consequently, language inputs are not thoroughly given. It will likely make students confused in taking language models provided. In addition, for university students, they have got similar text types since they were school students. It can hinder their vocabulary development. Also, they may be bored of getting those materials in their university level. In relation to vocabulary building, students usually open dictionary to help them know the meaning of unfamiliar words got when reading texts. However, teachers rarely provide following activities to assist students to improve their vocabulary. So, the students do not have sufficient opportunities to use the vocabulary productively. Hence, after they finish reading the texts, they may not remember new vocabulary they have just learned.

From the elaboration above, it can be seen that LbA can be an interesting idea to help students improve their vocabulary. It will become a new color to assist students in vocabulary building in Indonesian contexts. For the following activities, students are encouraged using words they have learned in contexts. To know their response toward the implementation of $\mathrm{LbA}$ to improve their vocabulary, the researcher conducted this research.

\section{LITERATURE REVIEW}

\section{LITERATURE-BASED APPROACH}

Literature-based Approach ( $\mathrm{LbA}$ ) is a real presentation to prove that literature and language cannot be separated. Language is used to compose literature. In point of fact, works of literature provide sources that shows the applications of language (Violetta-Irene, 2015). That is why this approach is implemented largely in language classrooms to teach not only language skills such as reading, writing, listening and speaking, but also language areas such as vocabulary, grammar, and pronunciation.

LbA offers some students benefits. Those benefits deals with what literature provides for students who are learning a new language. Using this approach, students will obtain knowledge about language, arts, and cultures. First, students have opportunities to see model of language used authentically. That is in line with Hipmanodlu (2005) and Norland and Pruett-Said (2006). They state that literary works are originally written to express what the writers feel and think, unlike texts written on purpose with vocabulary and grammar intentionally to develop a particular language skill. So, in applying the language, literary works are more natural and rich than 
designed texts, which are good as language input for the students. Second, students will be given the demonstration of arts while learning English. Not only literature shows students the application of language, it also demonstrates arts to the students. It can affect how students feel about the language learning process. Using art in language teaching, teachers can do more than working on students' cognitive aspects, like the language skills and language areas such as grammar, vocabulary, and pronunciation. Teachers can also develop students' affective skills (Violetta-Irene, 2015). By touching their affective skills, students will be more motivated in reading (Norland and PruettSaid, 2006). Third, LbA provide students with cultural knowledge. People do not need to go to a particular country to know its cultural values. Literary works are a brilliant way to know that. It is also stated by Hipmanoðlu (2005) who emphasizes that every literary work introduces culture through characters that come from different places and backgrounds which bring their culture learned. For example, in the work such as novels, short stories, or plays, the characters are described with setting of time, setting of place, social background, and situation happening around them. When reading the story, students will be invited to know the story and understand cultures introduced in the texts. For instance, two characters are involved in conversation in which they talk about a certain topic using specific expression. From the communication happens, students are encouraged to consider why it takes place and why the expressions are used. It is one of the ways for students to be able to comprehend the culture introduced in the story which is usually embedded with the language used.
However, the LbA also has weaknesses. The first weakness of this approach is derived from its authenticity. Because the material used is authentic and not simplified, it will be quite hard for beginners. Norland and Pruett-Said (2006) maintain that the approach is sufficiently effective for students from the intermediate to advanced level, but it does not work similarly for beginners. In other words, the language presented in the texts is commonly beyond the ability of elementary level students. Consequently, students will likely feel hard to understand the text and it can be hindrance to their reading motivation.

Another weakness of LbA is that some vocabulary is presented in a different way from what students know. It happens because within this approach, the words sometimes are used informally which may be new for students. The words usually used in a context or based on culture that they do not know. Norland and Pruett-Said (2006) state that for beginners, predicting the meaning of expressions or words that are used based on a culture or a context that they are not familiar with is quite frustrating.

The other weakness of this approach is regarding to the gap of values and cultures from the literary works and those that students hold. Students may come from different areas with their diverse values and cultures. Vice versa, literary works are also written by bringing cultures and thoughts that the author want to introduce to the readers. If students as readers find that cultures implanted in the texts are not in line with their personal beliefs, they will lose their enthusiasm to read the texts (Norland \& Pruett-Said, 2006). 


\section{NOVEL AS A READING MATERIAL}

Novels are one of literary works that can be employed as a reading material. Being used as a reading material, Hipmanoðlu (2005) mentions three benefits of using novels to students. First, presented with minimum illustration and more written description, students are demanded to imagine all things in the story such as the plot, setting, and movement that the characters in novels make. It challenges students' ability of fantasizing and imagining. Second, related to the content, novels are written with various conflicts, which are good to develop students' affective skills. Through the conflicts, students are able to identify emotions of each character and then they learn the way the characters deal with the problems so that they can do the same thing when they are in the same position. Briefly, students can also absorb wisdoms and values presented in the story. Third, novels have more storyboards than short stories. The storyboards told through written verbal description provide more language input. After absorbing the language input by reading and processing what they have learned, students are finally confident to practice the language through speaking or writing. It means that getting more input empowers students to perform the language (Folse, 2004).

In choosing the novel for English instruction, teachers need to be selective by considering some points. The novel used should have an interesting, entertaining, and motivating theme (Hipmanoðlu, 2005). Things related to students' personal life are a brilliant idea to attract their interest. Hipmanoðlu (2005) also points out that chosen novels should have contents appropriate for students' emotional and cognitive level. So, students' emotional and mental growth will be stable and not be distracted by an external factor from inappropriate books they read.

The last consideration is related to level of difficulty. If teachers want to use novels as a reading material, they should ensure that the material is not too hard for students. The difficulty level of the novels for English instruction can be defined from the vocabulary they used. Nation (2006) states that a good reading text should contain around $95 \%$ to $98 \%$ of known words and unfamiliar vocabulary to be learned by students is not more than $5 \%$ to $2 \%$. It is also in line with Input Hypothesis by Krashen (2003) which highlights that input should contain structure a bit beyond students' current level of competence. Paying attention to those two experts, it can be concluded that input is designed or selected to make students feel at ease in understanding the input without neglecting a portion of new vocabulary being learned.

In this research, a young adult novel was chosen for some reasons. First, the topic of this novel which tells about a boy's daily life and fun experiences is close to students' life. Second, because of daily life topic, vocabulary used is not extremely academic and difficult for students. That is in line with Nation (2006) and Krashen (2003). Third, the novel is completed with some illustrations for each story which can be effective to scaffold students in understanding the story.

\section{VOCABULARY BUILDING}

In building their vocabulary, students need to improve their knowledge about word meaning. According to Kamil and Hiebert (2005), to improve their knowledge of words, students are 
not only required to identify the words, but also to know the meaning of words and using them in a real context. In addition, Harmer (2007) proposes four aspects of vocabulary mastery that students need to build up. First, the students need to know the definition of the word. Second, students are required to know how to use the word in an appropriate level of formality which deal with word choice. Third, students need to understand word formation, which is related with the function or part of speech. Fourth, students need to know how to use the word in a correct grammatical form.

Those aspects are not an easy task for them. Consequently, EFL teachers, as the agent of change in the classroom where the students usually get English exposure, need to motivate them (Ahmadi, Ismail \& Abdullah, 2012). Besides providing suitable materials, teachers introduce students with techniques to build their vocabulary. One of techniques that are usually introduced by teachers is taking a note when students meet new words. Even though it is a conventional way in vocabulary building, Schmitt (2000) states that vocabulary notebooks are good to facilitate students in vocabulary learning because it can improve their self-management skills. With vocabulary notebooks, they are trained to know their own goals and needs when meeting some unfamiliar words.

Another technique is retelling. After getting vocabulary input by reading, students retell the story based on their reading. Without being asked to use the vocabulary, students automatically will do since the story they retell or rewrite is the same with the text. Even though it is impossible for them to use all words, at least some portions of words learned are employed. In parallel, Lee and Muncie (2006) highlight that using the words productively in writing is important to make students remember the target vocabulary learned.

\section{METHODOLOGY}

This research belongs to a descriptive qualitative research and obtained its data by interviewing five students who admitted that it was their first time in reading an English language novel. They were also chosen because they got the highest score on vocabulary from a group consisting of thirty-six students. To interview the participants, a guideline for semi guided interview was used as an instrument (see the appendix). The interview session was conducted using Indonesian language for two until three hours through G-chat for 4 participants and WhatsApp for one participant. After that, the data transcription from G-chat and WhatsApp were copied in to pages of Microsoft word application. Then, the researcher did member checking by calling the respondents one by one to ensure that the researcher. Next, the data were coded using three steps of coding such as open coding, axial coding, and selective coding. After coding, data analysis and discussion were presented based on categories shown below.

\section{THE TASKS}

In implementing $\mathrm{LbA}$ in a reading class, two ultimate goals of this instruction were developing students' attitude in reading and improving their vocabulary size. To achieve the goal, a novel that suits students' characteristics is selected. For the techniques, the teacher designed a set of activity 
to be done in the classroom. First, the teacher divided the books into some parts consisting of twenty to thirty pages to be read by the students per week outside the class. Second, in every meeting, students were put in small groups to have a discussion related to assigned pages they had read. Third, they were tested whether they read through a retelling quiz. Fourth, a vocabulary quiz was also conducted to help students recognize words that they got from reading which was conducted using a dictation quiz. Fifth, the teacher created an activity to help students more understand the story in the novel so that they could relate it to their own real life.

\section{FINDINGS}

\section{STUDENTS' PERCEPTION ON THE NOVEL CHOSEN}

Topic. Four students (Angga, Citra, Dita, and Erni) agreed that the novel chosen had an interesting topic able to develop their motivation in reading. Angga said that the book was interesting to follow. Beti stated that at the beginning, they felt intimidated because it was written fully in English and it was originally from an English speaking country. However, as time went by, she finally enjoyed the class after reading some pages and thought that the story in the novel was amusing. Like Beti, at the first time, Citra had negative attitude toward the novel since it was her first time reading an English language novel. However, after reading some pages, she changed her mind. She was more interested in the reading after knowing that the story of the novel chosen was great and entertaining. She stated that after reading three times, she claimed that the story was funny and could make her laugh. Then, she felt motivated in reading the book since she was curious what happened with the character in the next pages so that she kept reading the novel and finished it. Like the others, Dita perceived that the story of the novel was closely related to her own life. It made her interested in reading the novel. She also admitted that she liked the story so much that she could remember most of it even though the class had finished. She added that the novel used was appropriate for low level students because it was completed with illustration and the story was related to students' daily life. It made students feel at ease in understanding the story.

Vocabulary. In relation to vocabulary in the novel, all respondents agreed that the novel was a good choice to build their vocabulary mastery. Four students (Angga, Citra, Dita and Erni) stated the novel helped them know more about word formation in tenses (how to differentiate Verb 2 and Verb 3). Beti and Dita confessed that their knowledge of word derivation, like difference and different, suggest and suggestion, announce and announcement, was improved. Beti also stated that after reading, her knowledge about words in terms of synonym was also increased.

Citra and Erni added that the novel told about a kid's daily activities and experiences. The context was able to be found around the students and vocabulary dominantly used in the novel was familiar for them. In effect, they could feel easy in understanding the content. Even though some unfamiliar words were still found, it did not make them understand the story any less.

Culture. Besides topic and vocabulary, what made them excited to read the book was new information about culture presented in the novel. 
In relation with culture, Dita stated that it was good to read a novel that was originally from America since she learned something new. She was excited to know about thanksgiving that the characters celebrated.

\section{STUDENTS' PERCEPTION ON ACTIVITIES}

Based on the interviews, five students (Angga, Beti, Citra, Dita, and Erni) perceived that activities conducted in LbA such as vocabulary quizzes, retelling quizzes, group discussion, class discussion, and projects given can motivate them to read the novel and help them increase their vocabulary. Even though some of them (Beti, Citra, and Erni) admitted that the vocabulary quiz made them nervous coming to the class. However, they agreed to say that all activities done in LbA were successful to assist them building vocabulary. In line with it, Angga stated, reading the novel and all activities in literaturebased learning not only enabled them to know the meaning or definition but to know how to use words properly. Dita also agreed that activities done were able to increase their understanding about word definition and meaning.

Vocabulary Quizzes. Three students (Beti, Citra and Erni) stated that vocabulary quizzes made them feel under pressure. They felt that they were forced to read the novel if they wanted to get a good score. Beti stated that at the first time, she was stressed coming to the class because of the vocabulary quiz since she did not read the novel at all. Based on her confession, she should have read the book before coming to the class. If she did not read the book, she would not be able to answer vocabulary questions well and got a bad score. She admitted that the quiz made her frustrated. However, she stated that this quiz worked well to help improve her vocabulary mastery. Like Beti, Citra felt the same way. She was anxious coming to the class because she did not read so she was not prepared for the vocabulary quiz. In effect, she was not able to do classroom activities which dominantly tested the students whether they read. Having the same feeling like Beti and Citra, Erni stated that at the beginning she could not enjoy the class because she always felt frustrated. She did not prepare or read the novel. So, she worried that she would get a bad score for the vocabulary quiz. Even though they experienced an uninteresting thing in doing the vocabulary quiz because of lacking of preparation, they realized that this activity forced them to read. If the teacher did not apply this rule, students might have not read the novel.

Meanwhile, Angga and Dita were respondents who did not feel anxious with all classroom activities of LbA including vocabulary quiz. They said that reading the novel was interesting and their vocabulary mastery was improving after reading. Angga added that classroom activities such as vocabulary quizzes, retelling quizzes, group discussion, even the mid assignment, and the final project were all interesting for him. Both of them also agreed that because of the activities done in LbA especially vocabulary quiz, they could know the meaning of some unfamiliar words and they could also use the words in a right context accurately.

Even though three (Beti, Citra and Erni) of them felt frustrated because of this quiz, all of the respondents agreed that this activity was effective to push them to read. Vocabulary could also be improved by doing this activity. They also realized 
that because the vocabulary quiz is presented using dictation activity where the students wrote the words what the teacher said using a correct spelling, their word knowledge in terms of pronunciation and spelling was improved.

Retelling Quiz. Besides vocabulary quiz, there was also retelling quiz. Students perceived that this activity pushed them to read. If they did not read, they would submit a blank paper in this quiz and get a bad score. This activity was also a place where the students could use vocabulary in a context. Angga admitted that this quiz and vocabulary quiz were the purpose of why he read the novel. By doing this quiz, he did not only know the definition and meaning of unfamiliar words he found, but he also could use the words in a context. Like Angga, Beti said that she should prepare the quiz well by reading the novel. If she did not read it, she would not be able to retell the story comprehensively in retelling quiz. In parallel, Erni stated that this quiz forced her to read. She kept reading the novel not only once but three times or four times to really understand the story so that she could be fluent in retelling the story in the quiz.

\section{STUDENTS' PERCEPTION ON STRATEGIES TO BUILD VOCABULARY USING THE NOVEL}

The data from the interviews showed some techniques that students used to improve their vocabulary by reading the novel in LbA. After meeting new vocabulary that they were not familiar with, Beti, Citra, Dita and Erni usually would ask their friends to know the meaning. While Angga and Beti explained that they often opened a dictionary to solve the problem, Beti and Dita found out the meaning from a transla- tion tool in their smartphones. Then, Angga, Beti and Citra claimed that they guessed the meaning of the words from the context provided. They also admitted that after getting some new vocabulary, they do techniques to keep the vocabulary. Those techniques are taking notes and using the new words.

Taking notes. Students' effort to remember the words they found was by taking some notes. It could be like a vocabulary journal or annotation written directly on the novel. Beti stated that every time she got new words after reading, she noted them on a sticky memo then she stuck it on her room wall. Taking note was also Citra's preference to remember new words. She said that she wrote the words on a note book, and she thought that by writing the words, she was able to know how to spell the words correctly. Sometimes, she also made annotation directly on the novel by writing the Indonesian translation of the words. Doing like what Citra did, Dita and Erni usually circled words that she did not know. After that, they looked for the meaning of them and wrote it near the words they circled in the novel.

Using the new words. Besides taking some notes either on the book or directly on the novel, students used another technique to improve their vocabulary they learned from reading. Beti, Dita and Erni said that they used the vocabulary after reading in their retelling quiz. To retell the story they read in certain pages, they tried to use the new words they found as much as they could. Beti added that she also used the vocabulary in her writing projects for a mid-assignment which the topic was their dream and a final-assignment which was about their life experience. Then, Erni and Citra also stated that they not only employed 
the words in a writing task, but also used those words in speaking when they chatted with friends from the same department (English Education Department). Citra even still remembered what new words she used in the conversation, such as involved, wrap, klutzy and footstep. Dita added that one of the things that made her motivated to read the novel was because it was authentic so that it provided more vocabulary to learn.

\section{DISCUSSIONS}

The results of this research indicate that based on students' perception, the novel as the learning material and activities done in implementing LbA were effective to assist students in vocabulary building. Even though at the beginning three students (Beti, Citra and Erni) felt anxious when doing quizzes, they could enjoy it after some meetings. Based on the data, they felt anxious and nervous because it was their first time reading a novel in English language. They felt insecure reading an authentic text because of the language barrier. In contrast, two participants (Angga and Dita) admitted that they did not feel what the three participants felt. It might have been caused by their high level of English proficiency. It is in line with Norland and Pruett-Said (2006) who state that LbA works well for students with good English proficiency. For those whose English proficiency is still in a survivor level, LbA demands them to work harder in understanding the novel.

However, after reading some pages in several meetings, they felt interested for some reasons. First, the novel was considered to be fit for freshmen because the topic was near from their daily life so that some of them might have a similar experience with the characters. In addition, illustration was presented in the novel so that it could help students understand the story. Second, in terms vocabulary, since the topic was about daily life, vocabulary used in the novel was not too hard for them. Unfamiliar words did not hinder students' comprehension. It indicated that vocabulary used in the novel was not far from the students' capacity. It is in parallel with Nation (2006) who states that reading materials should contain $95 \%$ to $98 \%$ familiar words so that students can feel at ease in understanding the content. It is also supported by Krashen (2003) with his Input Hypothesis which states that learners need a comprehensible input in acquiring a new language. Comprehensible input itself is defined as an input given to the students should be little beyond their current understanding. From the data, it can be known that the novel was interesting since it was related to their students' daily life. Hipmanoðlu (2005) was in line with it by saying that reading material is supposed to be interesting and entertaining for students so that they will feel attracted to read more.

For the strategies in building vocabulary, when the students found unfamiliar words in reading, they made efforts to understand the meaning. From the data, it could be seen that the students seldom asked to the teachers. They tried to find the meaning by their own. It indicates that $\mathrm{LbA}$ is good to foster students' autonomous learning. That is in line with a research result done by Nassaji (2003) that LbA enables students to learn independently outside the classroom.

After getting new words, students did a following activity named retelling quiz. The teacher 
asked students to retell after reading the novel using their own words. Usually, in this session, they used the new words learned. This activity was like a trigger for students to use the words in contexts. It is in line with Lee and Muncie (2006) who highlight that using the words productively in writing is prominent to make students remember the target vocabulary learned well. Additionally, outside the class, some of them also used the words for speaking to their mates. So, it is true what Folse (2004) and Linse and Nunan (2005) say that by developing their vocabulary, students can perform the language well.

The results imply that in applying LbA for EFL students, teachers could introduce some short stories as short authentic texts first to provide scaffolding for the students before going on to reading a novel. It is because not all students have read an English language novel. Reading novel without giving a prior introduction with a more simple text will make them anxious and nervous joining activities in the classroom. It can demotivate them in reading an English text when they cannot understand what they read and finally get a dissatisfying score for it.

After getting sufficient experiences by reading short stories in English language, their confidence might be sufficiently shaped. Then, the teacher can give a higher level of literary work like a novel. By doing so, the students will not be stressed reading a novel. It is since if they are given a novel directly without preliminary, they may be anxious. So, they might have a negative perception before doing the task that could discourage them in reading.

\section{CONCLUSION}

LbA is a good idea applied for a reading class. However, students need a proper material. An English Education department of one university in Indonesia implemented the LbA using a novel. To encourage the students to read, the teacher supported it with activities such as a vocabulary quiz and retelling quiz. Based on the students' perception, the activities done are effective to push them read and improve their vocabulary even though some students felt frustrated and anxious at the beginning, but finally they admitted that they got benefits from the activities. Their frustration and anxiety were mainly caused by their lack of experiences in reading English texts. The feeling might have been caused by their unfamiliarity with a novel in English language. However, after reading several pages, students started to be interested in reading the book. So, it is suggested for teachers who want to implement LbA in an EFL context where the students are not familiar with an English language novel to start it by giving a simpler literary work like a short story first before using novels. With a short story, students who do not like reading will not be overwhelmed reading the long writing work written in the target language with unfamiliar vocabulary. Unlike novels, short stories are simple and short. It is good as preliminary materials before introducing students with novels.

In relation to the culture learned from the book, based on the result, students reported that Thanksgiving is the only culture introduced in the novel. In fact, there are still other culture values that can be dug more. The teacher is suggested to assist students to explore cultures 
embedded in the language learned from the novel. The culture may be related to the event or taboo and politeness in the country where the setting is explored described in the novel.

The conclusion is that teachers in EFL contexts may apply the approach to develop their interest in reading and help them build vocabulary. However, they had to know the students characteristics. By knowing their characteristics, teachers are able to know what material and what activities designed to support the process. However, it is strongly emphasized that by using literary work and LbA, students can build their vocabulary.

\section{REFERENCES}

Ahmadi, M., Ismail, H. \& Abdullah, M. (2013). The importance of metacognitive reading strategy awareness in reading comprehension. English Language Teaching, 6(10): 235-244.

Folse, K. (2004). Vocabulary myths: Applying second language research to classroom teaching. Ann Arbor, MI: University of Michigan Press. Harmer, J. (2007). The practice of English language teaching (4th edition). Essex: Pearson Education Ltd

Hiebert, E., \& Kamil, M. (2005). Teaching and learning vocabulary. Mahwah, NJ: Erlbaum.

Hipmanoðlu, M. (2005). Teaching English through literature. Journal of Language and Linguistic Studies, 1(1) 53-66.

Krashen, S. D. (2003). Explorations in language acquisition and use: The Taipei lectures. Portsmouth, N.H: Heinemann.

Lee, S.H., \& Muncie, J. (2006). From receptive to productive: Improving ESL learners' use of vocabulary in a postreading composition task.
TESOL Quarterly, 40, 295-320.

Linse, C. T. \&Nunan, D. (2005). Practical English language teaching: Young learners. New York: McGrawHill ESL/ELT.

Nassaji, H. (2003). L2 vocabulary learning from context: Strategies, knowledge sources, and their relationship with success in L2 lexical inferencing. TESOL Quarterly, 37, 645-670.

Nation, P. (2001). Learning vocabulary in another language. Cambridge, UK: Cambridge University Press.

Norland, D. L., \& Pruett-Said, T. (2006). A kaleidoscope of models and strategies for teaching English to speakers of other languages. Westport, Conn.: Teacher Ideas Press.

Schmitt, N. (2000). Vocabulary in language teaching. Cambridge University Press, Cambridge.

Tomlinson, B. (2011). Introduction: principles and procedures of materials development. In B. Tomlinson (ed.) Materials development in language teaching (second edition). Cambridge; Cambridge University Press, pp. 1-34.

Violetta-Irene, K. (2015). The use of literature in the language classroom: methods and aims. International Journal of Information and Education Technology, 5 (1), pp. 74-79. 


\section{0}

Journal of Foreign Language, Teaching $\mathcal{E}$ Learning Vol.1 No. 1 January 2016

\section{APPENDIX}

Questions of semi-guided interview used:

1. Bagaimana menurut Anda tentang kelas reading kemarin?

2. Bagaimana menurut Anda tentang novel yang di pakai?

3. Menurut Anda apakah dengan membaca novel di kelas reading yang Anda ikuti sekarang ini bisa meningkatkan vocabulary?

Ini kan pengalaman pertama membaca novel Bahasa Inggris. Bagaimana perasaan Anda? Apakah Anda mengalami kesulitan? Kesulitan soal vocab? Bagaimana cara Anda mengatasi kesulitan tersebut?

4. Setelah mendapatkan kosa kata baru, apa yang Anda lakukan untuk lebih memahami dan mengingatnya? 